09,10

\title{
Неупругий межмолекулярный обмен колебательными квантами и релаксация колебательно-возбужденных состояний в твердых бинарных системах
}

\author{
(C) А.Р. Алиев ${ }^{1,2}$, И.Р. Ахмедов ${ }^{1,3}$, М.Г. Какагасанов ${ }^{1,3}$, 3.А. Алиев ${ }^{1}$, \\ М.М. Гафуров ${ }^{1,3}$, К.Ш. Рабаданов ${ }^{2,3}$, А.М. Амиров ${ }^{3}$ \\ ${ }^{1}$ Институт физики им. Х.И. Амирханова ДагНЦ РАН, \\ Махачкала, Россия \\ 2 Дагестанский государственный университет, \\ Махачкала, Россия \\ ${ }^{3}$ Аналитический центр коллективного пользования ДагНЦ РАН \\ Махачкала, Россия \\ E-mail: amilaliev@rambler.ru
}

(Поступила в Редакцию 2 августа 2016 г.)

Методами спектроскопии комбинационного рассеяния изучены процессы молекулярной релаксации в твердых бинарных системах нитрат-перхлорат: $\mathrm{LiNO}_{3}-\mathrm{LiClO}_{4}, \mathrm{NaNO}_{3}-\mathrm{NaClO}_{4}$ и $\mathrm{KNO}_{3}-\mathrm{KClO}_{4}$. Обнаружено, что время релаксации колебания $v_{1}(A)$ аниона $\mathrm{NO}_{3}^{-}$в бинарной системе меньше, чем в индивидуальном нитрате. Показано, что увеличение скорости релаксации объясняется наличием в системе дополнительного механизма релаксации колебательно-возбужденных состояний нитрат-иона. Этот механизм связан с возбуждением колебания другого аниона $\left(\mathrm{ClO}_{4}^{-}\right)$и „рождением“ решеточного фонона. Установлено, что условием реализации такого релаксационного механизма является то, что разность частот указанных колебаний должна соответствовать области достаточно высокой плотности состояний фононного спектра.

КШР благодарит за поддержку РФФИ (проект № 16-33-60057_мол_а_дк).)

DOI: $10.21883 /$ FTT.2017.04.44276.316

\section{1. Введение}

Исследование процессов молекулярной релаксации методами колебательной спектроскопии дает богатую информацию о структурно-динамических свойствах конденсированной системы [1]. Такого рода исследования основаны на том факте, что ширины полос в колебательном спектре обратно пропорциональны временам молекулярной релаксации [2]. При этом каждый из релаксационных процессов вносит вклад в общую ширину колебательной полосы. Молекулярная релаксация может быть разделена на ориентационную [3] и колебательную [4]:

$$
\delta=\delta_{V}+\delta_{R},
$$

где $\delta$ - ширина колебательной линии, $\delta_{V}, \delta_{R}-$ вклады в ширину за счет процессов колебательной и ориентационной релаксации. Процессы колебательной релаксации в свою очередь подразделяются на адиабатические и неадиабатические [5]:

$$
\delta_{V}=\delta_{\mathrm{ad}}+\delta_{\text {nad }},
$$

где $\delta_{\text {ad }}, \delta_{\text {nad }}-$ вклады в ширину за счет адиабатических и неадиабатических процессов колебательной релаксации. Среди адиабатических наибольшее значение имеют процессы колебательной дефазировки [6]. К неадиабатическим процессам относится релаксация за счет отталкивательных [7], диполь-дипольных [8] и ион-дипольных [9] взаимодействий, а также резонансный обмен колебательными квантами [8] и внутримолеку- лярный распад колебательных состояний с участием фононов [10]. В последнем случае внутримолекулярная колебательная релаксация рассматриваемой моды сопровождается „рождением“ колебания с меньшей частотой и некоторым возмущением ближайшего окружения.

Учитывая все это, ширину колебательной полосы можно представить в виде суммы соответствующих вкладов [11-13]

$$
\delta=\delta_{\mathrm{dep}}+\delta_{\mathrm{dd}}+\delta_{\mathrm{id}}+\delta_{\text {rep }}+\delta_{\text {res }}+\delta_{\text {imp }}+\delta_{R} .
$$

Здесь $\delta_{\text {dep }}$ - вклад в ширину спектральной линии за счет колебательной дефазировки; $\delta_{\mathrm{dd}}, \delta_{\mathrm{id}}, \delta_{\text {rep }}-$ вклады за счет диполь-дипольных, ион-дипольных, отталкивательных взаимодействий, $\delta_{\text {res }}$ - вклад за счет резонансной передачи колебательных квантов, $\delta_{\text {imp }}$ вклад за счет процессов внутримолекулярного фононного распада колебательно-возбужденных состояний.

Целью настоящей работы являются анализ и сравнение процессов молекулярной релаксации в индивидуальных кристаллах и бинарных твердых системах, а также выявление возможных дополнительных механизмов релаксации колебательно-возбужденных состояний молекулярных ионов в бинарных твердых системах (по сравнению с индивидуальными кристаллами).

\section{2. Объекты исследования}

В соответствии с целью работы в качестве объектов исследования выбраны кристаллические нитрат 
лития $\left(\mathrm{LiNO}_{3}\right)$, перхлорат лития $\left(\mathrm{LiClO}_{4}\right)$, нитрат натрия $\left(\mathrm{NaNO}_{3}\right)$, перхлорат натрия $\left(\mathrm{NaClO}_{4}\right)$, нитрат калия $\left(\mathrm{KNO}_{3}\right)$, перхлорат калия $\left(\mathrm{KClO}_{4}\right)$, а также эквимолярные бинарные твердые системы нитрат лития-перхлорат лития $\left(\mathrm{LiNO}_{3}-\mathrm{LiClO}_{4}\right)$, нитрат натрия-перхлорат натрия $\left(\mathrm{NaNO}_{3}-\mathrm{NaClO}_{4}\right)$ и нитрат калия-перхлорат калия $\left(\mathrm{KNO}_{3}-\mathrm{KClO}_{4}\right)$.

Низкотемпературные фазы нитрата лития и нитрата натрия имеют ромбоэдрическую структуру кальцита, пространственная группа $R 3 c-D_{3 d}^{6} \quad[14-16]$ (гексагональные решетки $P 3 c[17])$. Низкотемпературная фаза нитрата калия имеет псевдогексагональную орторомбическую структуру арагонита, пространственная группа Pnта [16] (по другим данным ромбическая решетка $P m n b$ [17] или Pmcn [18-20]). Температуры плавления $\mathrm{LiNO}_{3}, \mathrm{NaNO}_{3}$ и $\mathrm{KNO}_{3}$ равны $T_{m}\left(\mathrm{LiNO}_{3}\right)=253-254^{\circ} \mathrm{C}$, $T_{m}\left(\mathrm{NaNO}_{3}\right)=306-307^{\circ} \mathrm{C}$ и $T_{m}\left(\mathrm{KNO}_{3}\right)=334.5^{\circ} \mathrm{C}[14-17]$. По нашим данным $T_{m}\left(\mathrm{LiNO}_{3}\right)=247.4^{\circ} \mathrm{C}$ и $T_{m}\left(\mathrm{NaNO}_{3}\right)=$ $=304.9^{\circ} \mathrm{C}$ (рис. 1,2 ). Нитраты натрия и калия переходят в разупорядоченные фазы $R 3 m$ при $T_{\mathrm{str}}\left(\mathrm{NaNO}_{3}\right)=276^{\circ} \mathrm{C}$ и $T_{\text {str }}\left(\mathrm{KNO}_{3}\right)=128-129^{\circ} \mathrm{C}$ [16-20]. По нашим данным $T_{\text {str }}\left(\mathrm{NaNO}_{3}\right)=271.9^{\circ} \mathrm{C}$ (рис. 2). Точечная группа симметрии нитрат-иона зависит от симметрии окружающих его полей [21]. При нарушении плоской структуры $\mathrm{NO}_{3}^{-}$в результате межмолекулярного взаимодействия в конденсированной среде можно ожидать понижение симметрии по схеме $D_{3 h}-C_{3 v}-C_{2 v}-C_{s}$. Для максимально симметричного (симметрия $D_{3 h}$ ) свободного нитратиона характерны четыре колебания, активные в спектрах комбинационного рассеяния (КР): $v_{1}(A)-$ валентное полносимметричное колебание $\left(1050 \mathrm{~cm}^{-1}\right), v_{2}(B)-$ валентное асимметричное колебание $\left(800 \mathrm{~cm}^{-1}\right), \nu_{3}(E)-$ неплоское деформационное дважды вырожденное колебание $\left(1300 \mathrm{~cm}^{-1}\right), v_{4}(E)$ - плоское деформационное дважды вырожденное колебание $\left(700 \mathrm{~cm}^{-1}\right)[11,21]$.

$\mathrm{LiClO}_{4}$ представляет собой бесцветный кристалл гексагонального типа группы $C_{6 v}^{4}$, температура плавления которого равна $T_{m}=247^{\circ} \mathrm{C}$ (по другим данным $T_{m}=236^{\circ} \mathrm{C}$ ), температура разложения составляет $400^{\circ} \mathrm{C}[14,17]$. По нашим данным $T_{m}\left(\mathrm{LiClO}_{4}\right)=244.6^{\circ} \mathrm{C}$ (рис. 1). $\mathrm{NaClO}_{4}$ по известным данным имеет две кристаллические модификации: низкотемпературную орторомбическую $\left(D_{2 h}^{17}-\mathrm{Cmcm}\right)$ и высокотемпературную ГЦК $\left(O_{h}^{5}-F m 3 m\right)$, температура перехода равна $T_{\text {str }}\left(\mathrm{NaClO}_{4}\right)=306-308^{\circ} \mathrm{C}$, температура плавления $T_{m}=469^{\circ} \mathrm{C} \quad[14,17]$. По нашим данным $T_{\text {str }}\left(\mathrm{NaClO}_{4}\right)=308.3^{\circ} \mathrm{C}, T_{m}\left(\mathrm{NaClO}_{4}\right)=472.3^{\circ} \mathrm{C}$ (рис. 2,3 ). Низкотемпературная фаза перхлората калия $\mathrm{KClO}_{4}$ имеет орторомбическую структуру типа барита, пространственная группа Рпта. При $T_{\text {str }}\left(\mathrm{KClO}_{4}\right)=300^{\circ} \mathrm{C}$ происходит переход в кубическую структуру с пространственной группой $T^{4}[14]$. В расплаве благодаря сферической симметрии перхлорат-ион находится в свободном вращении. Отношение к тетраэдрической системе предполагает следующие элементы симметрии: три взаимно перпендикулярные оси второго порядка, четыре оси симметрии третьего порядка и шесть плоскостей симметрии, проходящих через каждые две из четырех

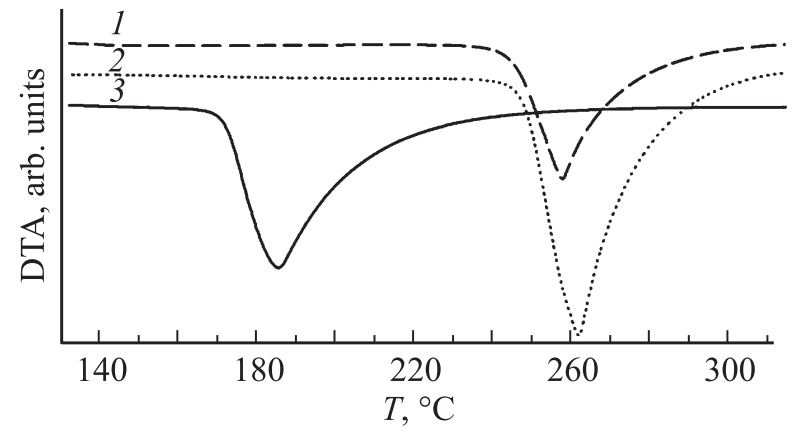

Рис. 1. Кривые ДТА $\mathrm{LiClO}_{4} \quad$ (1), $\mathrm{LiNO}_{3} \quad$ (2), $0.5 \mathrm{LiNO}_{3}-0.5 \mathrm{LiClO}_{4}(3)$.

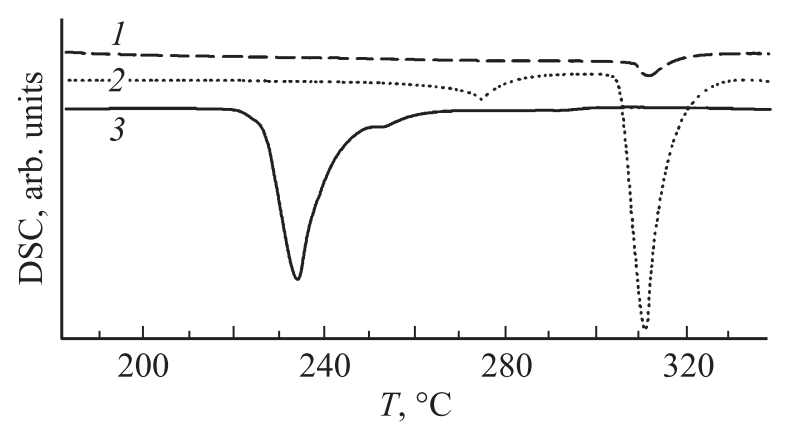

Рис. 2. Кривые ДСК $\mathrm{NaClO}_{4}$ (1), $\mathrm{NaNO}_{3}$ (2), $0.5 \mathrm{NaNO}_{3}-$ $-0.5 \mathrm{NaClO}_{4}(3)$.

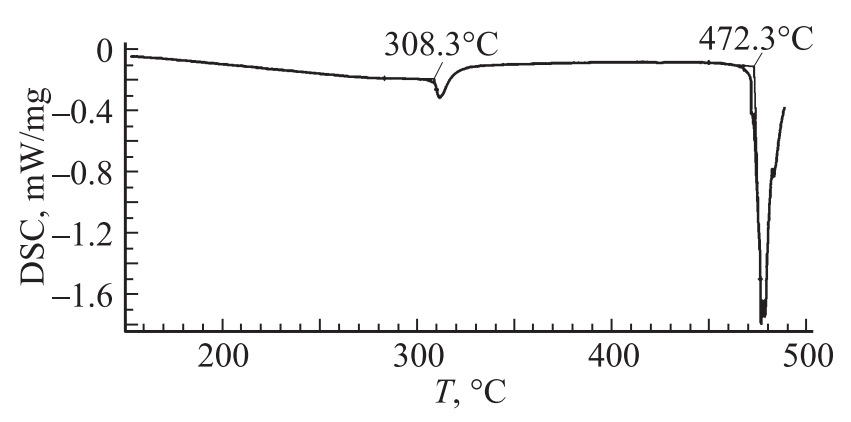

Рис. 3. Кривая ДСК $\mathrm{NaClO}_{4}$.

осей третьего порядка. Перхлорат-ион $\mathrm{ClO}_{4}^{-}$(симметрия $T_{d}$ ) характеризуется следующими активными в КР колебаниями: $v_{1}(A)$ - валентное полносимметричное колебание $\left(963 \mathrm{~cm}^{-1}\right), v_{2}(E)$ - дважды вырожденное колебание $\left(455 ;(463 ; 467) \mathrm{cm}^{-1}\right), v_{3}\left(F_{2}\right)$ - трижды вырожденное колебание $\left(1058 ;(1094 ; 1110) ; 1142 \mathrm{~cm}^{-1}\right)$, $v_{4}\left(F_{2}\right)$ - трижды вырожденное колебание $(619 ; 657$; $\left.665 \mathrm{~cm}^{-1}\right)$ [22].

Эквимолярная система нитрат-перхлорат приготавливалась смешиванием предварительно прогретых при температуре $150^{\circ} \mathrm{C}$ мелкодисперсных порошков нитрата и перхлората. Полученная смесь медленно нагревалась до температуры, при которой гарантированно расплавятся оба компонента $\left(270^{\circ} \mathrm{C}\right.$ для $\left.\mathrm{LiNO}_{3}-\mathrm{LiClO}_{4}\right)$ или один из компонентов $\left(320^{\circ} \mathrm{C}\right.$ для $\mathrm{NaNO}_{3}-\mathrm{NaClO}_{4}$ и $350^{\circ} \mathrm{C}$ для $\left.\mathrm{KNO}_{3}-\mathrm{KClO}_{4}\right)$. В последних двух случаях при достиже- 
нии указанных температур гарантированно расплавится соответствующий нитрат, а перхлорат растворится в расплаве нитрата. Затем полученная бинарная система медленно охлаждается и кристаллизуется. В такой системе концентрации анионов $\mathrm{NO}_{3}^{-}$и $\mathrm{ClO}_{4}^{-}$совпадают. При этом происходит образование твердых растворов замещения и равномерное распределение анионов $\mathrm{NO}_{3}^{-}$ и $\mathrm{ClO}_{4}^{-}$по кристаллической решетке [23]. Синтез проводился в атмосфере сухого аргона в Аналитическом центре коллективного пользования Дагестанского научного центра РАН (АЦКП ДагНЦ РАН). Эквимолярная система $\mathrm{LiNO}_{3}-\mathrm{LiClO}_{4}$ плавится при температуре $170^{\circ} \mathrm{C}[24]$, по нашим данным при $170.9^{\circ} \mathrm{C}$ (рис. 1). Эквимолярная система $\mathrm{NaNO}_{3}-\mathrm{NaClO}_{4}$ по данным наших калориметрических измерений (рис. 2) плавится при температуре $226.5^{\circ} \mathrm{C}$.

\section{3. Эксперимент}

Дифференциальный термический анализ (ДТА) (дифференциальная сканирующая калориметрия (ДСК)) проводился на приборе синхронного термического анализа STA 449 F3 Jupiter („NETZSCH“6) при скорости нагрева $10 \mathrm{~K} / \mathrm{min}$ в атмосфере аргона в алундовых тиглях (рис. 1-3) в АЦКП ДагНЦ РАН. Обработка данных и интегрирование пиков проводились с помощью встроенных прикладных программ фирмы „NETZSCH“.

Для получения информации о динамических межионных взаимодействиях нами использован анализ формы контуров колебаний молекулярных анионов в спектрах КР твердой системы. Непосредственно из фононного спектра получить подобную информацию не представляется возможным. Спектр малых частот высокотемпературных фаз ионных кристаллов, как правило, регистрируется в виде широкой бесструктурной полосы, обусловленной термическим смешением различных типов (трансляционных, либрационных) внешних колебаний структурных единиц.

Концентрационные изменения состава твердой системы также слабо проявляются в спектрах малых частот ионных кристаллов и расплавов, содержащих молекулярные ионы [25]. В то же время изменения структуры и динамики твердой системы оказывают влияние на колебательные состояния ее структурных единиц и отражаются в спектрах инфракрасного поглощения и КР. Поэтому использование колебательных спектров, соответствующих внутренним модам молекулярных ионов, для получения информации о процессах молекулярной релаксации в ионных кристаллах и расплавах представляется вполне обоснованным.

Спектры КР возбуждались излучением аргонового лазера ЛГ-106м-1 с длиной волны $\lambda=488 \mathrm{~nm}$ и регистрировались спектрометром ДФС-52М в области колебаний $v_{1}\left(\mathrm{NO}_{3}^{-}\right)$и $v_{1}\left(\mathrm{ClO}_{4}^{-}\right)$от 850 до $1150 \mathrm{~cm}^{-1}$ в температурном интервале $25-350^{\circ} \mathrm{C}$. Ширины входной и выходной щелей монохроматора устанавливались одинаковыми и в зависимости от интенсивности рассеяния выбирались равными от 100 до $200 \mu \mathrm{m}$. Положения максимумов колебательных полос фиксировались с точностью $\pm 0.5 \mathrm{~cm}^{-1}$, а их ширины - с точностью $\pm 0.1 \mathrm{~cm}^{-1}$. Температура образцов поддерживалась в процессе регистрации спектров с точностью $\pm 0.5 \mathrm{~K}$. Методика регистрации и обработки спектров КР подробно описана в [11-13].

На рис. 4 показаны спектры КР твердых систем $\mathrm{LiNO}_{3}-\mathrm{LiClO}_{4}, \mathrm{NaNO}_{3}-\mathrm{NaClO}_{4}, \mathrm{KNO}_{3}-\mathrm{KClO}_{4}$ в области колебаний $v_{1}$ анионов $\mathrm{NO}_{3}^{-}$и $\mathrm{ClO}_{4}^{-}$. Контуры рассматриваемых колебаний резкополяризованы (изотропное рассеяние), и потому их формирование всецело можно приписать процессам колебательной релаксации.

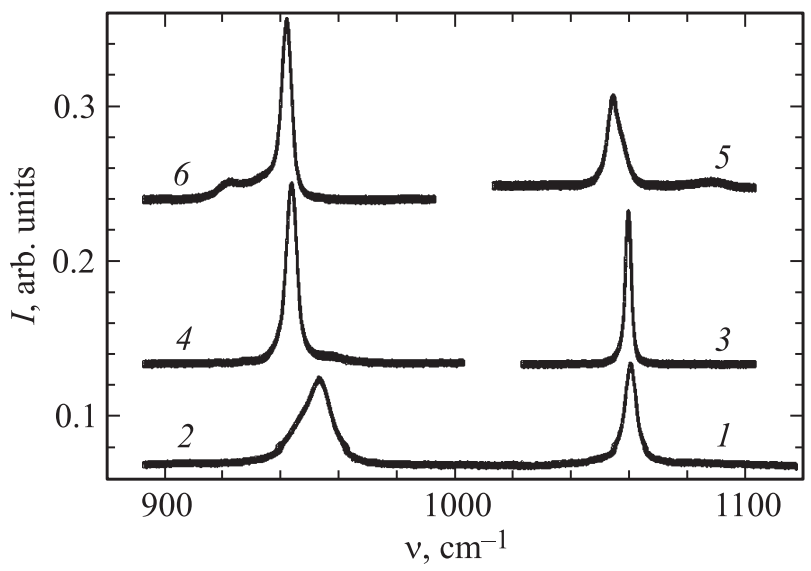

Рис. 4. Спектры КР твердых бинарных систем $\mathrm{LiNO}_{3}-\mathrm{LiClO}_{4}$ при температуре $T=75^{\circ} \mathrm{C} \quad(1,2), \mathrm{NaNO}_{3}-\mathrm{NaClO}_{4}$ при $T=25^{\circ} \mathrm{C}(3,4)$ и $\mathrm{KNO}_{3}-\mathrm{KClO}_{4}$ при $T=50^{\circ} \mathrm{C}(5,6)$ в области валентных полносимметричных колебаний $v_{1}(A)$ нитрат-иона $\mathrm{NO}_{3}^{-}(1,3,5)$ и перхлорат-иона $\mathrm{ClO}_{4}^{-}(2,4,6)$ при ширинах входной и выходной щелей монохроматора $100(1,3)$ и $150 \mu \mathrm{m}(2,4-6)$.

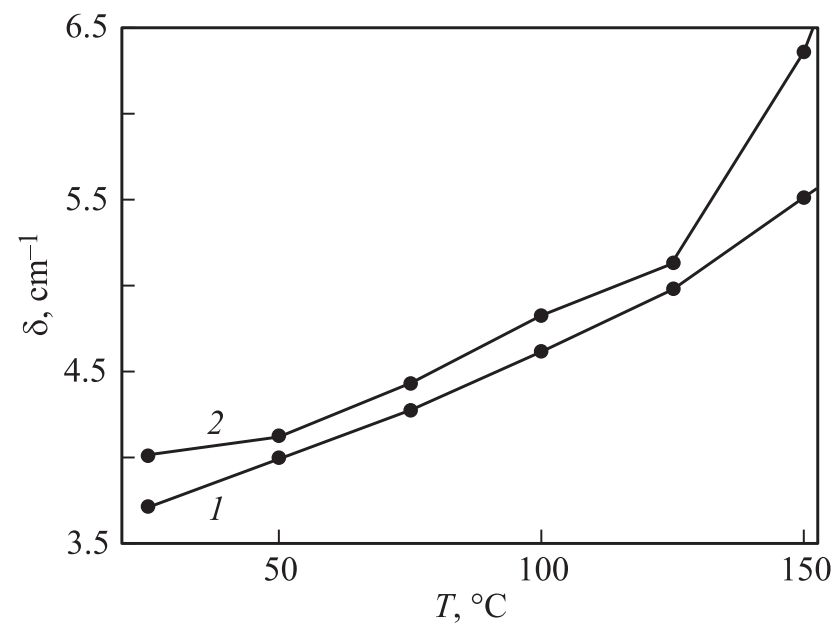

Рис. 5. Сравнение температурных зависимостей ширины спектральной линии КР в области валентного полносимметричного колебания $v_{1}(A)$ нитрат-иона $\mathrm{NO}_{3}^{-}$в нитрате лития $\mathrm{LiNO}_{3}(1)$ и в системе $\mathrm{LiNO}_{3}-\mathrm{LiClO}_{4}(2)$. 


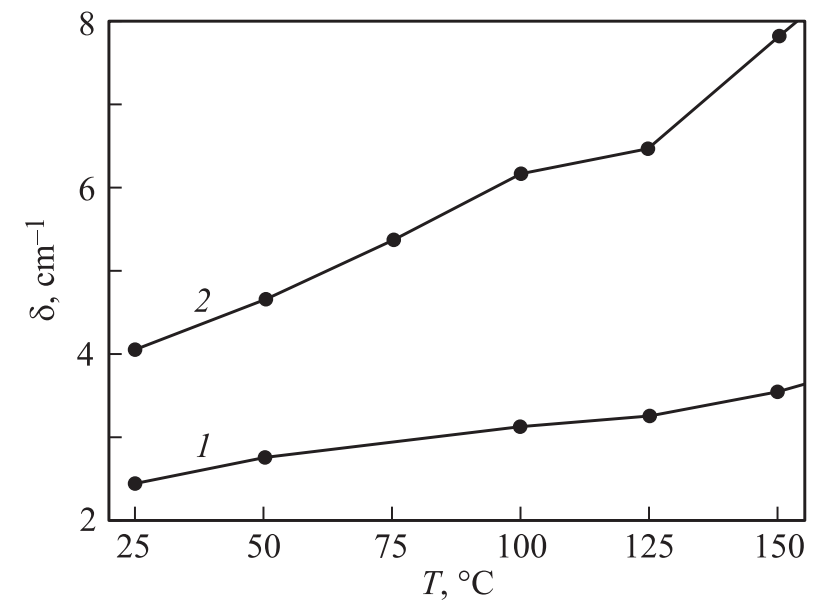

Рис. 6. Сравнение температурных зависимостей ширины спектральной линии КР в области валентного полносимметричного колебания $v_{1}(A)$ нитрат-иона $\mathrm{NO}_{3}^{-}$в $\mathrm{NaNO}_{3}(1)$ и в системе $\mathrm{NaNO}_{3}-\mathrm{NaClO}_{4}(2)$.

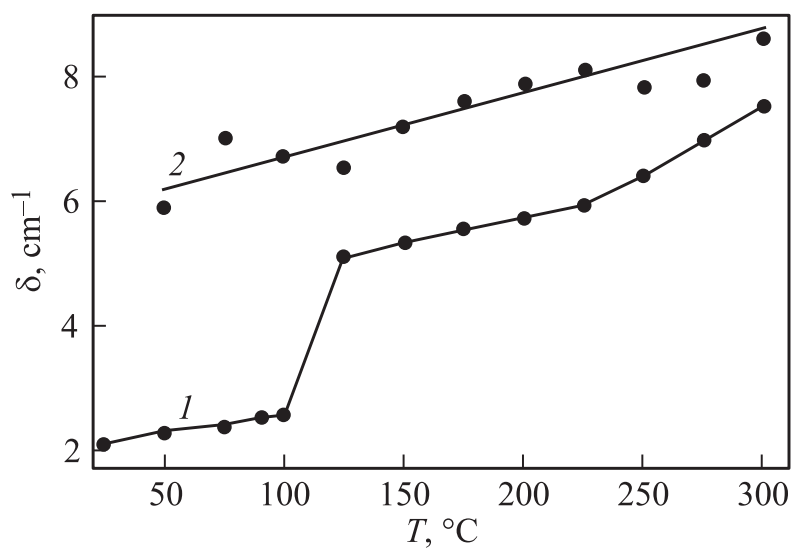

Рис. 7. Сравнение температурных зависимостей ширины спектральной линии КР в области валентного полносимметричного колебания $v_{1}(A)$ нитрат-иона $\mathrm{NO}_{3}^{-}$в $\mathrm{KNO}_{3}(1)$ и в системе $\mathrm{KNO}_{3}-\mathrm{KClO}_{4}(2)$.

На рис. 5-7 представлены температурные зависимости ширин $\delta$ контура $v_{1}(A)$ колебания $\mathrm{NO}_{3}^{-}$в кристаллах $\mathrm{LiNO}_{3}, \mathrm{NaNO}_{3}$ и $\mathrm{KNO}_{3}$ и в бинарных системах $\mathrm{LiNO}_{3}-\mathrm{LiClO}_{4}, \mathrm{NaNO}_{3}-\mathrm{NaClO}_{4}$ и $\mathrm{KNO}_{3}-\mathrm{KClO}_{4}$ соответственно. Сравнение ширин $\delta$ контура колебания $v_{1}(A)$ $\mathrm{NO}_{3}^{-}$в бинарных системах с соответствующими данными для кристаллов $\mathrm{LiNO}_{3}, \mathrm{NaNO}_{3}$ и $\mathrm{KNO}_{3}$ показывает, что величины $\delta$ и скорость температурного уширения значительно выше в спектре КР бинарных систем $\mathrm{LiNO}_{3}-\mathrm{LiClO}_{4}, \mathrm{NaNO}_{3}-\mathrm{NaClO}_{4}$ и $\mathrm{KNO}_{3}-\mathrm{KClO}_{4}$.

\section{4. Обсуждение результатов}

Попытки связать значения частот полносимметричного валентного колебания нитрат-иона с физическими параметрами одновалентных нитратов делались неодно- кратно [12]. Температурно-фазовую зависимость частот колебаний можно объяснить в рамках модели, согласно которой причина частотного сдвига связана с изменением равновесных длин связей и ангармоничности соответствующих колебаний сложного иона в результате нарушения теплового баланса [13].

Все перечисленные выше факторы молекулярной релаксации, имеющие место в индивидуальных кристаллах, актуальны и для бинарных твердых систем. Следует иметь в виду, что в бинарной твердой системе структура исходных кристаллов меняется и это может сказаться на изменении характеристик соответствующих спектральных переходов. Однако в бинарных твердых системах, имеющих два сорта молекулярных ионов, возможен еще один релаксационный механизм, если различные молекулярные ионы имеют близкие по частотам внутримолекулярные колебания (ВМК). При этом релаксация колебания $v_{i}$ молекулярного иона одного сорта может сопровождаться возбуждением соответствующего колебания $v_{j}$ молекулярного иона другого сорта, а разница энергий может передаваться фононам решетки. Такой неупругий межмолекулярный обмен колебательными квантами реализуется при условиях

$$
\begin{aligned}
& v_{i}>v_{j}, \\
& v_{i}-v_{j}<v_{m}=k_{\mathrm{B}} T_{\mathrm{D}}(h c)^{-1}=T_{D} \cdot 0.6038 \mathrm{~cm}^{-1} \cdot \mathrm{K}^{-1},
\end{aligned}
$$

где $v_{m}$ - максимальная частота фононного спектра (в $\left.\mathrm{cm}^{-1}\right), T_{D}$ - температура Дебая (в $\left.\mathrm{K}\right)$. Если $T_{D}=200 \mathrm{~K}$, то $v_{m}=139 \mathrm{~cm}^{-1}$. Обычно для ионных и молекулярных кристаллов $T_{D}>200 \mathrm{~K}$ и соответственно $v_{m}>139 \mathrm{~cm}^{-1}$. Поэтому несложно подобрать бинарную твердую систему, для которой выполняются условия (4).

Тогда ширину колебательной полосы бинарной твердой системы можно представить в виде

$$
\delta=\delta_{\text {dep }}+\delta_{\text {dd }}+\delta_{\text {id }}+\delta_{\text {rep }}+\delta_{\text {res }}+\delta_{\text {imp }}+\delta_{\text {emp }}+\delta_{R},
$$

$\delta_{\text {emp }}$ - вклад в ширину спектральной линии за счет процессов релаксации колебательно-возбужденных состояний, связанных с неупругим межмолекулярным обменом колебательными квантами.

В бинарных твердых системах нитрат-перхлорат условия (4) выполняются, если в качестве колебания $v_{i}$ выбрать колебание $v_{1}\left(\mathrm{NO}_{3}^{-}\right) \approx 1050-1070 \mathrm{~cm}^{-1}$, а в качестве колебания $v_{j}$ выбрать колебание $v_{1}\left(\mathrm{ClO}_{4}^{-}\right) \approx 950-960 \mathrm{~cm}^{-1}$ [26-28]. Разность частот этих колебаний составляет $v_{i}-v_{j} \approx 90-120 \mathrm{~cm}^{-1}$.

Частоты внешних (фононных) колебаний $\mathrm{LiNO}_{3}$, $\mathrm{NaNO}_{3}, \mathrm{KNO}_{3}$ не превышают $350,250,180 \mathrm{~cm}^{-1}$ соответственно [21]. Эти значения можно рассматривать как максимальные частоты $v_{m}$ фононного спектра. Они согласуются с данными о температурах Дебая, которые в ряду нитратов $\mathrm{LiNO}_{3}, \mathrm{NaNO}_{3}, \mathrm{KNO}_{3}$ убывают как 446, 375 (367 K [29]), 230 K [21]. Мы не нашли в литературе данных о температуре Дебая для перхлоратов, но для 
близкого к ним кристалла $\mathrm{NaClO}_{3} T_{D}=320 \mathrm{~K}$ [30]. Поэтому мы можем считать, что в бинарных твердых системах нитрат-перхлорат $T_{D}>200 \mathrm{~K}$ и соответственно $v_{m}>139 \mathrm{~cm}^{-1}$. При этом разность частот $v_{i}-v_{j}$ колебаний нитрат-иона и перхлорат-иона будет меньше, чем максимальная частота $v_{m}$ фононного спектра системы, и условие (4) окажется выполненным. Следовательно, возможна диссипация колебательной энергии ВМК нитратиона с последующим возбуждением соответствующего ВМК перхлорат-иона и „рождением“ решеточного фонона, так как разница в частотах указанных ВМК попадает в область достаточно высокой плотности состояний фононного спектра исследуемых кристаллов [31,32].

\section{5. Заключение}

Таким образом, установлено, что имеют место факторы, способствующие увеличению скорости релаксации внутримолекулярных колебательных мод в бинарных твердых системах по сравнению с таковой для индивидуальных кристаллов. По нашему мнению, объяснение данного экспериментального факта можно найти, если допустить наличие дополнительного механизма релаксации колебательно-возбужденных состояний в бинарных твердых системах. При реализации этого механизма возможен обмен колебательными квантами между различными молекулами или молекулярными ионами с близкими значениями частот внутримолекулярных колебаний. Такой неупругий межмолекулярный обмен должен сопровождаться „рождением“ решеточного фонона, который забирает разницу между энергиями релаксирующего и возбуждаемого колебаний. Поэтому предлагаемый механизм релаксации актуален, когда разность частот этих колебаний меньше, чем максимальная частота фононного спектра системы.

\section{Список литературы}

[1] Ю.К. Воронько, А.А. Соболь, В.Е. Шукшин. ФТТ 49, 1871 (2007).

[2] А.В. Раков. Тр. ФИАН СССР 27, 111 (1964).

[3] К.А. Валиев, Е.Н. Иванов. УФН 109, 31 (1973).

[4] В.Е. Погорелов, А.И. Лизенгевич, И.И. Кондиленко, Г.П. Буян. УФН 127, 683 (1979).

[5] С.А. Кириллов. В сб.: Динамические свойства молекул и конденсированных систем / Под ред. А.Н. Лазарева. Наука, Л. (1988). С. 190.

[6] D.W. Oxtoby. J. Chem. Phys. 70, 2605 (1978).

[7] К.А. Валиев. ЖЭТФ 40, 1832 (1961).

[8] К.А. Валиев. Опт. и спектр. 11, 465 (1961).

[9] К. Сарка, С.А. Кириллов. Укр. физ. журн. 26, 1118 (1981).

[10] М.А. Иванов, Л.Б. Квашина, М.А. Кривоглаз. ФТТ 7, 2047 (1965).

[11] М.М. Гафуров, А.Р. Алиев. Расплавы 2, 41 (2000).

[12] А.Р. Алиев, М.М. Гафуров. ЖФХ 75, 477 (2001).

[13] A.R. Aliev, M.M. Gafurov, I.R. Akhmedov. Chem. Phys. Lett. 359, 262 (2002).
[14] Е.Ю. Тонков. Фазовые диаграммы соединений при высоком давлении. Наука, М. (1983). 280 с.

[15] В.Н. Беломестных, А.А. Ботаки. ФТТ 32, 2829 (1990).

[16] В.Н. Беломестных, А.А. Ботаки. ФТТ 34, 261 (1992).

[17] Химическая энциклопедия. Сов. энциклопедия, М. (1990). T. 2. C. 288,608 ; (1992). T. 3. C. $183-184$.

[18] С.В. Барышников, Е.В. Чарная, А.Ю. Милинский, Е.В. Стукова, C. Tien, D. Michel. ФТT 52, 365 (2010).

[19] С.В. Барышников, Е.В. Чарная, А.Ю. Милинский, Ю.А. Шацкая, D. Michel. ФТТ 54, 594 (2012).

[20] С.В. Барышников, Е.В. Чарная, А.Ю. Милинский, Ю.В. Патрушев. ФТТ 55, 2439 (2013).

[21] Д.В. Корабельников, Ю.Н. Журавлев. ФТТ 55, 1651 (2013).

[22] В.Д. Присяжный, В.И. Снежков. Укр. хим. журн. 47, 230 (1981).

[23] Т.Ю. Дробчик, Р.Ш. Халиуллин, В.А. Невоструев. Ползуновский вестник 2, 92 (2006).

[24] M.M. Markowitz. J. Phys. Chem. 62, 827 (1958).

[25] M.H. Brooker, G.N. Papatheodorou. In: Advances in molten salt chemistry. V. 5 / Ed. G. Mamantov. Elsevier, Amsterdam (1983). P. 26.

[26] К. Кольрауш. Спектры комбинационного рассеяния. ИЛ, M. (1952). $466 \mathrm{c.}$

[27] Л.М. Свердлов, М.А. Ковнер, Е.П. Крайнов. Колебательные спектры многоатомных молекул. Наука, М. (1970). $559 \mathrm{c}$.

[28] The Aldrich library of infrared spectra / 2nd ed. C.J. Pouchert, Aldrich Chemical Company Inc. (1978). P. 292.

[29] В.Н. Беломестных, Е.П. Теслева. Изв. Томск. политехн. унта 307, 6, 11 (2004).

[30] В.Н. Беломестных, Э.Г. Соболева. Фундам. пробл. соврем. материаловедения 6, 1, 112 (2009).

[31] D.W. James, W.H. Leong. J. Chem. Phys. 49, 5089 (1968).

[32] W.H. Leong, D.W. James. Austral. J. Chem. 22, 499 (1969). 